\title{
Layered inorganic-organic clay-like nanocomposites rearrange to form silsesquioxanes on acid treatment
}

Guruswamy Kumaraswamy, * Yogesh Deshmukh, Vikrant V. Agrawal and P. Rajmohanan

Polymer Science and Engineering Division, National Chemical Laboratory, Pune, India. Fax: 91-20-

2589-3234; Tel: 91-20-2589-3382; E-mail: guru@poly.ncl.res.in

\section{SEM of Ph clay:}

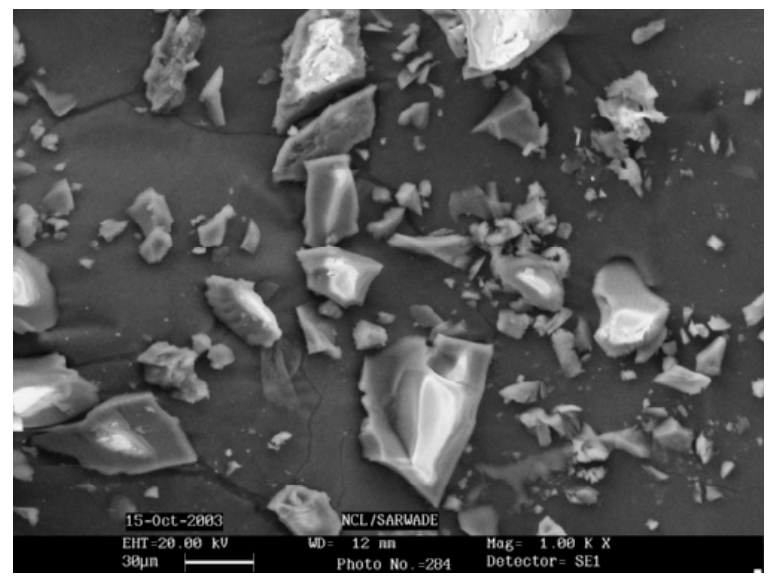

Figure S1: Plate-like structures observed in the SEM of Ph clay. SEM was done using a Leica-S-440 microscope at accelerating voltage of $20 \mathrm{kV}$. 
Acid treatment of Laponite-RD and natural talc:
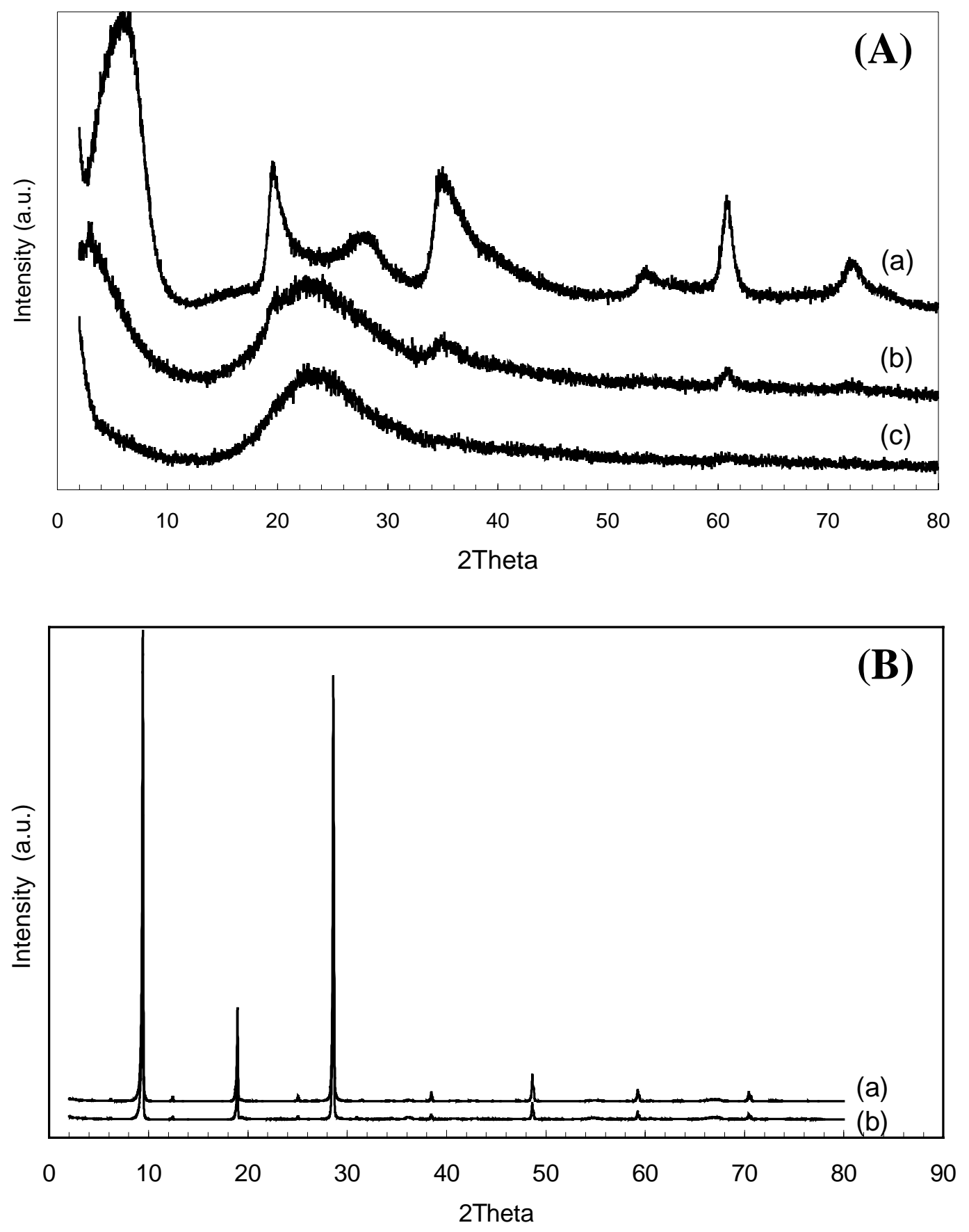
Figure S-2: XRD of (A)-laponite (a) Laponite RD, (b) Laponite RD Acid treated for 2min (c) Laponite RD Acid treated for 10min and (B)-natural talc before and after acid treatment using $3 \mathrm{M} \mathrm{HCl}$ for various durations. (a) Talc acid treated with $3 \mathrm{M} \mathrm{HCL}$ (b) Talc. The XRD scans are plotted on a linear scale and vertically offset for clarity. Laponite-RD is a product of Laporte industries; natural talc was obtained from B.S Mica Pvt. Ltd. Both clays were used as received.

\section{Solution NMR of acid treated Ph clay:}

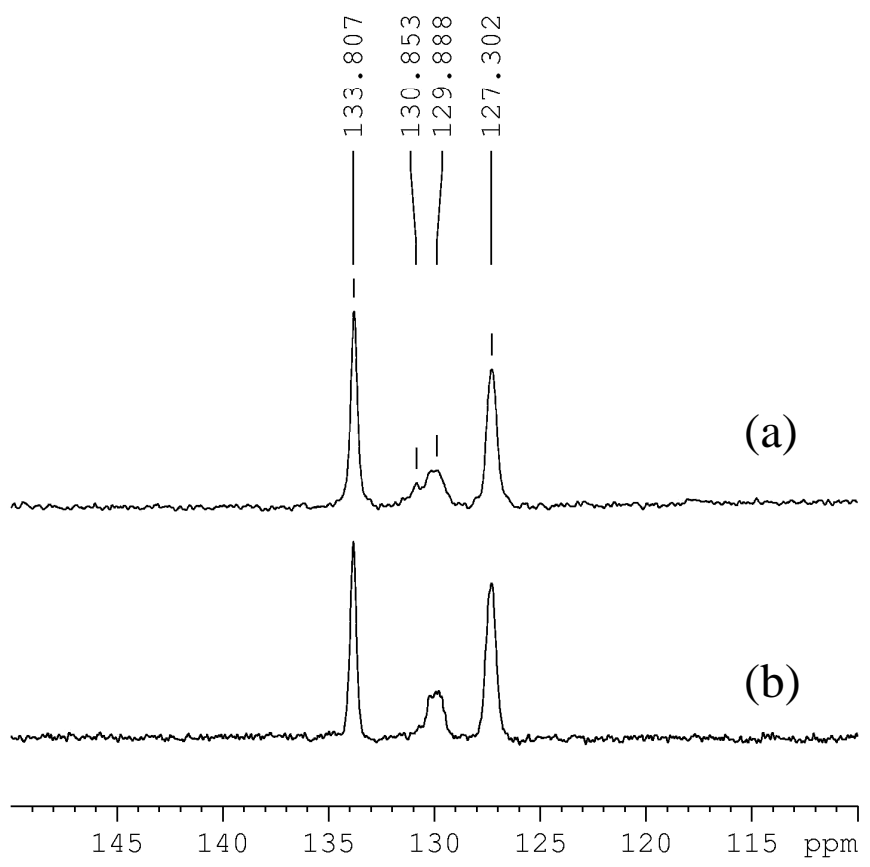

Figure S-3: Comparison of the $125 \mathrm{MHz}$ (a) proton decoupled ${ }^{13} \mathrm{C}$ spectrum and (b) DEPT spectrum of the acid treated $\mathrm{Ph}$ clay taken in $\mathrm{CDCl}_{3}$. The signal that is absent in the DEPT spectrum is the carbon atom of the phenyl ring to which the $\mathrm{Si}$ atom is attached. 
$\mathrm{Ph}$ clay is not soluble in organic solvents. Therefore, we cannot obtain solution spectra of $\mathrm{Ph}$ clay and can only obtain solid state spectra where the linewidths are broadened. However, the acid treated compound can be dissolved in deuterated chloroform to yield a ${ }^{13} \mathrm{C}$ solution spectrum. A comparison of the proton-decoupled ${ }^{13} \mathrm{C}$ spectrum (Figure $\mathrm{S}-3$ a) with the DEPT spectrum (Figure $\mathrm{S}-3 \mathrm{~b}$ ) taken in $\mathrm{CDCl}_{3}$ shows that the carbon atom attached to the silicon can be resolved at around $131 \mathrm{ppm}$, viz. acid treatment of the $\mathrm{Ph}$ clay does not cleave the $\mathrm{Si}-\mathrm{C}$ bond. Note that the solution spectra shows considerable narrowing of the peaks relative to the solid state spectra for the same compound (Fig. 4 in main paper). 